\title{
REFLEXIONES PRELIMINARES SOBRE UNA APLICACIÓN CIENTÍFICO-MÉDICA DE ACTUALIDAD: LA CLONACIÓN
}

\author{
José Antonio Arranz, Xavier Ariza, Encarnació Riudor, Lluis Vilar, Jordi \\ Salvadó, Núria Galofré, Susana Vendrell, Josep Maria Esquirol *
}

\begin{abstract}
Resumen: Este artículo afronta el nuevo reto que la tecnociencia médica ha abierto: la posibilidad de clonación terapéutica o reproductiva. En el presente trabajo se aborda, clara y esquemáticamente, la terminología científico-médica, desde los conceptos de reproducción sexual o asexual hasta la endonucleación, pasando por los conceptos de embrión gamético, somático, de cultivo y células madres, para ir realizando un análisis de los conflictos éticos que se abren en cada caso. La última parte del ensayo se centra en el problema ético del embrión y los problemas generados por los embriones sobrantes de los procesos de fertilización in vitro, origen de una importante controversia entre la comunidad científica, que pide que sean utilizados para fines de investigación, diferentes grupos sociales que se oponen a su utilización y la ley que los declara como no utilizables para fines reproductivos cuando su viabilidad no pueda ser garantizada.
\end{abstract}

Palabras clave: Clonación, bioética, aborto

\section{PRELIMINAR REFLECTIONS ABOUT A PRESENT TECHNO MEDICAL APPLICATION: CLONATION}

\begin{abstract}
This paper reflects about the new medical technoscience challenge opened: the possibility of therapeutic or reproductive clonation. The present paper approximates the medical-scientific terminology clearly and schematically, from the concepts of sexual or asexual reproduction to endonucleation, to the concepts of germinal, somatic or in vitro embryos and stem cells, to carry out an analysis of the ethical conflicts opened in each case. The last part of the essay centers in ethical issues related to the embryo, particularly the problems generated by the surplus embryos of fertilization in vitro, origin of an important controversy between the scientific community, that would like that they be utilized for research, different social groups, that opposed to their use, and the law, that declares them unusabel for reproductive purposes when their viability cannot be guaranteed.
\end{abstract}

Key words: Clonation, bioethics, abortion

\section{REFLEXÕES PRELIMINARES SOBRE UMA APLICAÇÃO CIENTÍFICO-MÉDICA DE ATUALIDADE: DA CLONAGEM}

Resumo: Este artigo confronta o novo desafio que a tecnociência médica abriu: a possibilidade de clonagem terapêutica ou reprodutiva. O presente trabalho aborda de uma forma clara e esquemática, a terminologia científico-médica, a partir dos conceitos de reprodução sexual ou assexual até a endo-nucleação, passando pelos conceitos de embrião gamético, somático, de cultivos e células tronco, para analisar os conflitos éticos que surgem em cada caso. A última parte do ensaio centra-se no problema ético do embrião e nos problemas criados pelos embriões excedentes dos processos de fertilização in vitro, origem de uma importante controvérsia entre a comunidade científica, que pede que sejam utilizados para fines de pesquisa, diferentes grupos sociais que se opõe à sua utilização e a lei que os declara como não utilizáveis para fins reprodutivos, quando sua viabilidade não pode ser garantida.

Palavras chave: Clonagem, bioética, aborto

* Grupo No 2 sobre la Responsabilidad Humana en Ciencia y Tecnología. Institut de Tecnoètica. Fundación Epson. Barcelona. Correspondencia: arranz@scs.vhebron.es 


\section{Introducción}

El término "clonación" es una de esas palabras que ha pasado directamente de las novelas y películas de ciencia-ficción al vocabulario habitual del ciudadano medio y a la realidad científico-médica de las sociedades desarrolladas, como la nuestra. Las claves de este trasvase han sido, por una parte, los avances ciertamente trascendentes en ciertas técnicas de manipulación y proliferación celular y la posibilidad de obtención de células madre pluripotenciales, pero, por otra parte y sobre todo, el interés desmedido que los medios de comunicación de masas han puesto sobre él, contribuyendo a su difusión. ¿Por qué los medios de comunicación occidentales han fijado de manera tan estentórea su mirada sobre este tema, cuando, habitualmente, relegan las cuestiones científicas, de tanta o más importancia que ésta, junto a las páginas de sociedad, rodeadas de noticias sobre bodas y bautizos o sucesos morbosos de la cruda realidad?

La experiencia de nuestro grupo de reflexión nos indica que uno de los factores que puede estar influyendo decisivamente en los sensacionalismos mediáticos, en las posturas más o menos intransigentes $y$, en general, en los desencuentros entre las diferentes partes del debate es el desconocimiento o el mal uso de los conceptos, términos y fundamentos de aquello de lo que se está hablando. No nos referimos a los detalles más o menos técnicos del laboratorio, sino a los significados concretos de las palabras y a la realidad científica actual de las mismas, fuera de los sesgos que la literatura de evasión, el cine, etc., han introducido en ellas.

Por ello no nos parece mala idea comenzar este esbozo de reflexiones heterodoxas con un breve repaso al vocabulario y al "state of the art" de este tipo de tecnologías y conocimientos, que nos permita empezar a desbrozar el campo y, tal vez, distinguir entre realidad y fan- tasía. Si bien es verdad que esta fantasía está sugestionada y alimentada por los mitos y tabúes o los anhelos más íntimos de nuestra tribu, como el significado de la procreación y de la vida, el destino inexorable del orden natural y el impulso que siempre ha movido al hombre a explorar y crear sistemas filosófico-ideológicos sobre su propia trascendencia, es decir, la superación por el ser humano de las barreras físicas, biológicas o naturales que restringen su existencia como individuo diferenciado, único y limitado en el tiempo.

\section{Resumen de terminología y actualidad científica}

Para empezar, los seres vivos se reproducen biológicamente mediante dos estrategias, la asexual y la sexual. La asexual consiste en la producción de descendientes completamente idénticos a partir de un progenitor, simplemente por reparto igualitario y al azar (lo que puede originar algún sesgo) del material de partida y por transferencia a los descendientes de copias idénticas del material hereditario del progenitor. Este tipo de reproducción, natural o inducida en el laboratorio, es lo que se puede denominar clonación, y clon es el individuo que procede de un mismo progenitor por este sistema. Es un sistema rápido, muy eficiente en la calidad de las copias, relativamente sencillo, que permite la creación de enormes cantidades de nuevos individuos en muy poco tiempo y que garantiza la estabilidad y conservación en el espacio y en el tiempo de las propiedades más esenciales de los seres vivos. Es el más empleado en la escala celular y por los seres vivos con menor complejidad. Por el contrario, la reproducción sexual es un mecanismo mucho más complejo y sofisticado que implica la recombinación del material hereditario propio y el intercambio o fusión con el material hereditario de un individuo diferente. Es menos eficiente que la asexual en cuanto a li- 
mitaciones biológicas y fisicoquímicas (energéticas), es más lenta y produce mucha menos progenie. Permite la innovación controlada (no las azarosas y peligrosas mutaciones), la generación de diversidad sutil y no desequilibrante y la transmisión de los cambios con mejor resultado adaptativo al resto de los individuos de la misma especie. En otras palabras, la reproducción sexual hace posible la evolución biológica continua de los seres vivos y su adaptación al medio.

El siguiente concepto clave es el de embrión: conjunto de células indiferenciadas derivadas directamente del cigoto u óvulo fecundado, que posteriormente, bajo ciertas condiciones y sometidas a los apropiados estímulos, originarán los diferentes tejidos de un individuo nuevo y/o al individuo nuevo completo. Los embriones que se suelen utilizar en la investigación de aplicaciones terapéuticas tienen unos pocos días. Se propone el límite de los 14 días, que es el momento en que comienza a aparecer el primitivo pliegue que después originará el tubo neural. De hecho, hasta transcurridos esos 14 días, no se puede diferenciar entre las células que formarán el verdadero embrión y las que formarán la placenta, y también hasta este momento el embrión se puede dividir en dos o más partes que originarán otros tantos individuos (como es el caso de los gemelos). Podemos distinguir varios tipos de embriones que, posiblemente, tienen repercusiones éticas diferentes. Uno es el embrión gamético, originado por la fusión entre un óvulo y un espermatozoide, y es el "común" o el "natural". El otro es el embrión somático, el "artificial", producido en el laboratorio por enucleación de un óvulo y su sustitución por el núcleo de una célula somática adulta. Se puede hacer otra distinción entre el embrión en cultivo en el laboratorio y el embrión implantado en el útero materno. En el útero materno puede desarrollarse hacia un nuevo ser, mientras que en un tubo de ensayo carece de potencial algu- no, excepto morir rápidamente si no se toman estrictas precauciones o es implantado.

Algunas de las células del embrión, adecuadamente cultivadas, originan las denominadas células madre, células pluripotenciales indiferenciadas que se renuevan a sí mismas indefinidamente y que, bajo ciertas condiciones, pueden diferenciarse en cualquier tipo celular. Las células madre también pueden obtenerse de la médula ósea de individuos adultos o de la sangre de cordón umbilical, pero, al parecer y por ahora, tienen menor potencial de diferenciación que las derivadas de embriones. Aunque todavía se encuentra en su fase preliminar, la investigación con células madre ofrece esperanza a millones de personas que sufren enfermedades como diabetes, enfermedad de Parkinson, lesiones traumáticas en la médula espinal, etc., de que tejido sano cultivado a partir de estas células pueda algún día utilizarse para sustituir sus tejidos enfermos o lesionados. No hay muchas otras opciones terapéuticas en el horizonte científico para muchas de estas enfermedades.

El término clonación terapéutica se refiere a los métodos utilizados para crear células madre que podrían ser utilizadas para producir tejidos nuevos. En teoría, esta metodología se puede aplicar tanto partiendo de embriones gaméticos como somáticos. Sin embargo, hay un problema en las técnicas de trasplante de tejidos u órganos que influye decisivamente en que células derivadas de ambos tipos de embriones tengan aplicaciones diferentes, con su repercusión ética asociada: el problema del rechazo del injerto por el sistema inmunitario del receptor. Este problema se puede presentar con los tejidos derivados de embriones gaméticos puesto que tienen un origen genético diferente del receptor (también se puede presentar con tejidos derivados de células madre adultas si su origen no es el mismo receptor). Para supe- 
rar este problema (y también para superar objeciones éticas, en teoría) se ideó y desarrolló el embrión somático, en el cual la información genética puede proceder de una célula adulta del propio receptor del trasplante y, por tanto, no habría rechazo de un injerto derivado de este embrión, puesto que sería reconocido como propio por el receptor. Muchos científicos prefieren no utilizar el término clonación terapéutica porque podría ser entendido como la creación de un clon humano para fines terapéuticos. En su lugar se prefiere el uso del término "transferencia de núcleo de célula somática", refiriéndose a las técnicas de cultivo celular in vitro descritas antes y asumiéndose que las aplicaciones terapéuticas futuras sólo tienen utilidad empleando células madre derivadas de embriones somáticos.

De este modo, el uso que se le podría dar a las células madre derivadas de embriones gaméticos se limitaría a investigación básica y aplicada de los mecanismos de diferenciación celular, pero no a aplicaciones terapéuticas concretas.

Si bien ya existía un importante bagaje metodológico y de conocimientos, la primera aproximación tecnológica que permitió validar el método de transferencia de núcleo de célula somática fue la creación de la oveja Dolly por el grupo de Wilmut en Escocia. Se partió de 400 óvulos que, tras enucleación y transferencia de núcleo somático, permitieron obtener unos 275 embriones. Luego de la estimulación de proliferación sólo 9 siguieron un desarrollo correcto y, de éstos, varios presentaban aberraciones. Al final, tan sólo quedó uno aparentemente adecuado y, tras el implante en el útero de una oveja madre, siguió una gestación y nacimiento de un nuevo individuo, completamente normal: Dolly. Este experimento fue un éxito aparente, pero también contribuyó a poner de manifiesto las limitaciones actuales en téc- nica y conocimientos. Posteriormente, se han obtenido por este procedimiento otros animales completos, como ratas, vacas y otros, y se ha comprobado que, en este tipo de individuos, la tasa de malformaciones, envejecimiento prematuro, cáncer y otras anomalías es muy superior a la que se observa en la naturaleza. Todo ello resalta lo rudimentario de la metodología y lo lejos que estamos de su aplicación real terapéutica. Además, supone el primer y más importante impedimento ético asumido por la comunidad científica que es, probablemente, el primer imperativo del trabajo científico, esto es, no se puede aplicar una tecnología cuando la metodología no funciona adecuadamente. Pero, a la vez, se ha generado un clamor entre la comunidad científica para que, lejos de ser un punto y final, se genere un importante estímulo para la financiación pública de la investigación básica que nos permita profundizar en los mecanismos que subyacen a la diferenciación celular. Se ha sugerido que el material más apropiado para esta investigación son los embriones congelados sobrantes de los métodos de fertilización in vitro a los que, tras muchos años de congelación y dada su imposibilidad para uso reproductivo, sólo les queda el destino de ser destruidos o congelados indefinidamente. Este aprovechamiento, aparentemente inocuo de unas células inservibles, genera todo tipo de recelos éticos en ciertos ambientes por lo que se supone una falta de respeto a unos supuestos seres humanos en potencia.

Aunque la finalidad última de los animales clonados era el desarrollo de una tecnología que permitiría la producción de sustancias de interés humano (proteínas, fármacos, hormonas, anticuerpos, etc.) de un modo muy asequible y con aplicabilidad comercial (por ejemplo, la proteína de interés se produciría en la glándula mamaria del animal y después se obtendría fácilmente y en grandes cantidades de la leche ordeñada), evidentemente este tipo de experi- 
mentos puso de manifiesto otro tipo de aplicación que podría resultar de los mismos: su uso como técnica reproductiva. A partir de aquí se empezó a hablar de clonación reproductiva, o utilización de estos métodos para crear seres nuevos idénticos a un molde elegido del que se dispusiera de material biológico viable. Fue este uso el que despertó, como no podía ser de otra manera, el sensacionalismo mediático y el que ha alimentado peligrosos caldos de cultivo sectarios (grupos, sobre todo en EEUU, con importantes fuentes de financiamiento, que proponen cosas tan peregrinas como clonar a Elvis o a Jesucristo, o que se aprovechan del dolor de familias que han perdido seres queridos para estafarlas descaradamente prometiendo milagrosas reencarnaciones) o religiosos o pseudomédicos oscuros (como las turbias intenciones del ginecólogo S. Antinori). Todo ello ha despertado el recelo, el miedo atávico (similar al de los desastres del año mil) y el rechazo de sectores de la población en general y de los políticos hacia toda la investigación en este campo, incluida la clonación terapéutica, lo que se ha traducido en EE.UU. en el bloqueo por el ex presidente Clinton (confirmado y ampliado por el actual presidente Bush) de todos los fondos públicos para investigación en células madre.

Desde el punto estrictamente médico, se ha de decir que la clonación reproductiva no tiene probablemente ninguna aplicación terapéutica (aun suponiendo que hoy fuera viable en el ser humano); no aporta nada que mejore los actuales sistemas de tratamiento de la infertilidad.

Y además, desde el punto de vista científico, se ha de decir que la idea de que clonar puede servir para obtener dos seres humanos idénticos es simplemente equivocada y por varios motivos. No hay nada más falso que afirmar que la esencia de un ser humano es una ristra de letras contenida en el material hereditario (el ADN) de una célula, sea ésta un cigoto na- tural o una célula de la uña. Además, cuando se transfiere un núcleo somático del supuesto molde humano elegido para clonar a un óvulo enucleado, sólo se transfiere la información contenida en ese núcleo; pero existe otra información trascendental para el desarrollo de ese cigoto nuevo: la que aporta el citoplasma (el resto de la célula que no es el núcleo) del óvulo "nodriza", entre la que hay otros sistemas genéticos (el ADN mitocondrial) y un universo de sustancias, microestructuras y equilibrios propios de ese óvulo, naturalmente muy similar a otros óvulos humanos, pero con sutiles diferencias aportadas por la propia individualidad del donante y que tienen ya, en primera instancia, una influencia en el desarrollo de una nueva individualidad del cigoto cuando se combinan con las órdenes contenidas en el ADN del núcleo donante. También, tras la implantación de este cigoto nuevo en el útero de una madre, comienza a recibir de ésta una cascada de información propia de esta madre y de sus circunstancias en ese momento, que no tiene nada que ver con la recibida en su día por el individuo molde que se pretende copiar. Entre esta información hay desde la calidad y la cantidad de los alimentos, la regulación metabólica particular, los estímulos hormonales, inmunológicos, tóxicos, y quién sabe cuántos más de carácter fisiológico, y no menos los estímulos de carácter psicológico como las emociones, los cuidados, las sensaciones, etc. Todo en conjunto crea, durante la gestación, una influencia única e irrepetible sobre la nueva vida que perfila un nuevo individuo. Por último, una de las cosas que diferencia al ser humano de otros seres vivos es que, cuantitativamente, en el ser humano la influencia del ambiente externo sobre el individuo es muy superior, modulando decisivamente la rígida impronta genética de nuestra herencia que, en cierto modo, esclaviza a los otros seres vivos. No es casualidad que el recién nacido humano sea el más desvalido entre todo el resto de seres vivos. Sólo contie- 
ne la estructura y funciones básicas y queda a merced de su entorno (su madre, padre, el medio físico, la educación, el cuidado y todo aquello que los seres humanos aportamos en la constitución de una nueva persona) para el desarrollo de funciones tan básicas para los humanos como la estructuración psicológica y el desarrollo de las funciones cerebrales superiores (inteligencia, etc.).

Resumiendo, se obtendrá un individuo que puede parecerse físicamente al molde, pero que será una persona completamente diferente. Para demostrarlo, véase a los gemelos idénticos naturales, sí verdaderos clones biológicos puesto que proceden de la partición de la misma célula y han recibido la misma influencia materna; aún así, son dos personas diferentes.

\section{EI problema del embrión}

Ya hemos visto que el embrión es un pequeño grupo de células pluripotenciales que derivan todas de la división celular de la primera célula o cigoto y que, en ellas, residen las instrucciones que se utilizarán para producir las estructuras anatómicas y los sistemas fisiológicos de un nuevo ser humano.

La cuestión ética fundamental que aquí se plantea es que para ciertos sectores de la sociedad el embrión tiene valor intrínseco desde el momento de la fecundación o concepción, subrayando la idea de que en ese momento un nuevo ser humano fue creado. Así, el cigoto o el embrión sería ya un ser humano (algunos hablan de un ser humano "en potencia") y merecería los derechos y el respeto debidos a cualquier ser humano. El resto de cuestiones, como el diferente estadio de desarrollo, si está en cultivo en un tubo o si está implantado en un útero, si es un embrión gamético o somático, o la finalidad con la que haya sido creado o cuál vaya a ser su futuro, son secundarias para los defensores de esta postura. Por tanto, un em- brión no podría ser manipulado o utilizado para ningún fin que no fuera el de permitir su desarrollo hasta convertirse en un nuevo individuo. Como corolario, no se debería crear ningún embrión que no tuviera como fin en sí mismo una nueva persona y nunca una nueva persona podría ser creada como medio para otro fin, fuera lo noble que fuera. Además, ningún beneficio que se pudiera proporcionar a personas ya nacidas justificaría la destrucción de una persona no nacida (un embrión), incluso si esta persona no se desarrollara más allá del estadio de pocas células: el respeto a la dignidad humana lo impediría.

Alguna voz discretamente discordante afirma que nadie puede saber $\mathrm{o}$, al menos, que hoy no se sabe qué es en realidad un cigoto o embrión de pocos días. En otras palabras, es un misterio si la humanidad reside o no en estas células y, por lo tanto, merecerían el respeto como seres humanos hasta que se demuestre lo contrario.

Frente a estas visiones se encuentra el modelo que podríamos denominar ambiental, que considera que en un conjunto de células indiferenciadas que llevan en su interior un programa genético de instrucciones no está un ser humano. Éste va apareciendo progresivamente a medida que el embrión va creciendo en el interior del útero materno y va recibiendo influencias maternas, primero y, después, del entorno exterior tras el nacimiento: influencias culturales y físicas y, finalmente, derivadas también de las propias decisiones de este nuevo ser a lo largo de su vida. Nadie se atreve a poner una frontera clara y tal vez no exista. Para los defensores de esta visión, afirmar que la humanidad reside en un programa genético contenido en un saco de proteínas y membranas denominado célula y que, indudablemente, es un ente vivo es una afirmación incompleta y parcial. 
Es curioso como la visión del modelo ambiental recupera una antiquísima tradición cristiana según la cual el embrión de pocos meses tiene todavía que adquirir "un alma" (modernamente diríamos: "un conjunto de influencias que lo dotarán de la categoría de ser humano"). Y también es curioso que la visión del valor intrínseco, en su obsesión por equiparar vida humana con persona humana, se acerca peligrosamente a las visiones geneticistas o deterministas ("todo está ya programado") tan en boga en círculos académicos y sociales americanos de la segunda mitad del siglo XX.

Es imposible no reconocer en esta confrontación antagónica la reedición del debate del aborto con posturas prácticamente calcadas, puesto que, para los "activistas del derecho a la vida", persona es igual a vida. Esta contaminación dificulta el llegar a acercamientos en el debate de los usos futuros de las células madre.

Pero es en el terreno de las preguntas o temas concretos donde se puede visualizar mejor el supuesto abismo que separa ambas posturas; o las posibilidades de acercamiento pragmático si se está dispuesto a valorar y a distinguir diferentes situaciones y matices.

\section{¿Tiene repercusión ética el origen de un embrión?}

Ya hemos visto que, por su origen, puede haber dos tipos de embriones: el "natural" o gamético y el "artificial" o somático. El adjetivo "natural" quiere poner de manifiesto que el embrión gamético se genera cuando se fusionan un espermatozoide y un óvulo, mientras que "artificial" resalta que el embrión somático procede de la fusión de material biológico no destinado a la reproducción. Algunos han querido ver en ello una razón para justificar una diferente valoración ética. Así el embrión gamético tendría un valor superior puesto que se produce siguiendo el procedimiento diseña- do por la naturaleza para generar un nuevo individuo, mientras que el somático sólo se produce en el laboratorio reprogramando o, si se prefiere, manipulando el destino de material genético no "propio" de este fin. Se asigna así un valor ético intrínseco a la categoría de lo "natural". Lo natural o biológico tendría una consideración ética superior a lo artificial o humano.

Sin embargo, si se tiene en cuenta cuál sería el resultado final de ambos tipos de embriones cuando fueran implantados en un útero materno -nuevos seres, íntegros, con su propia individualidad, pero indistinguibles bajo cualquier consideración-, parece difícil asumir tal valoración. Pero, tal vez, los que sostienen esta diferencia tienen en mente no los fines reproductivos sino los de investigación o los terapéuticos y están sugiriendo, implícitamente, reservar los embriones gaméticos para la finalidad reproductiva y su no utilización para los otros fines.

Esta sutil matización ética es la base sobre la cual se sustenta una de las grandes controversias actuales, expresada en la siguiente pregunta clave:

\section{¿Qué hacer con los embriones sobrantes de los programas de fertilización in vitro?}

Dadas las limitaciones técnicas de esta metodología, es necesario producir muchos embriones adicionales para garantizar el objetivo de un embarazo viable, por lo que se va generando una reserva creciente de miles y miles de embriones sobrantes que no se utiliza. En general, las legislaciones contemplan que, cuando no hay permiso de la pareja donadora o cuando ha pasado un tiempo de almacenamiento prudencial por encima del cual no se puede garantizar la viabilidad de los embriones, éstos no se pueden utilizar ya para fines reproductivos. También, en general, hay un clamor en la 
comunidad científica para que se permita la utilización con fines de investigación básica, sobre todo con el fin de conocer mejor los mecanismos de la diferenciación celular, puesto que la investigación aplicada con el objetivo de obtener células madre con uso terapéutico está limitada porque, salvo excepciones, no coincidiría el material genético del embrión con el de los futuros receptores de las células madre derivadas de él.

La justificación está en que estos embriones están destinados a su destrucción o a su congelación indefinida. Luego, aun bajo cualquier supuesto ético, sería un fin noble su aprovechamiento para, como mínimo, contribuir a incrementar nuestro conocimiento de los mecanismos de la vida y, posiblemente, con aplicaciones futuras en la curación o alivio de enfermedades muy graves que lastran la vida de millones de personas. No parece obvio que esta finalidad viole la dignidad natural que se debe asignar a un embrión humano, incluso si se participa de la visión del valor intrínseco. Sin embargo, esta opción choca frontalmente con las convicciones más íntimas de un sector de la sociedad (las de la visión del valor intrínseco), resultantes de nuestros condicionantes históricos de todo orden. La justificación de esta última postura está en dos conceptos: la superioridad ética de los fines naturales y, por tanto, la inviolabilidad del destino de los embriones gaméticos para el fin con el que fueron creados; $y$, en segundo lugar, la idea, aparentemente irrefutable, de que un ser humano (y un embrión lo es, para esta visión) no puede ser nunca un medio sino un fin en sí mismo. Por lo tanto no se podrían utilizar embriones (personas) para curar a otras personas. Además, como los embriones son personas, gozarían de todos sus derechos, por lo que no podrían ser manipulados o discriminados bajo ningún concepto.

Parece difícil encontrar algún consenso bajo estas premisas. Al contrario, parece que se en- cuentran nuevos recursos argumentales y una línea con coherencia global para expandir la visión del valor intrínseco a otros temas fronterizos. Así, por ejemplo, se encuentra una razón para descalificar el diagnóstico preimplantacional (selección de embriones en función de anomalías genéticas) o la contracepción, alegando el derecho del óvulo a que no sea manipulado su destino natural que es ser fertilizado por un espermatozoide. Se ha de decir que no todos los participantes de la visión del valor intrínseco, probablemente, llegarán a estas deducciones partiendo de las mismas premisas.

Otro tema afectado directamente por la argumentación es el sentido de las propias técnicas de fertilización in vitro. Así, si esta metodología no está lo suficientemente desarrollada desde el punto de vista técnico como para garantizar la no generación de embriones sobrantes que no se podrán implantar, entonces, desde este punto de vista, queda éticamente en entredicho puesto que estos embriones son relegados a la categoría de material de desecho y queda vulnerada así, gravemente, su dignidad como seres humanos, o como seres humanos en potencia. Sin embargo, pocos médicos -y la sociedad en general- negarán hoy en día la utilidad de estos métodos para solucionar graves problemas, como la infertilidad. Aún más, muy pocos, incluso dentro de la visión del valor intrínseco, se plantearían su prohibición bajo las anteriores premisas.

Nos enfrentamos con contradicciones de la sociedad y de la clase médica que no resultan nuevas puesto que, de una manera u otra, siempre han estado presentes en el sempiterno debate sobre el progreso científico. Además, dada la rapidez con la que se está generando el conocimiento científico, muchas veces, sólo tras un tiempo de desarrollo y valoración de las aplicaciones tecnológicas, se está en disposición de efectuar un análisis ético del conocimiento o metodología originales, cuando, tal 
vez, están ya plenamente implantados y asumidos por la sociedad.

\section{¿Cómo influyen otros matices sobre el embrión en la valoración ética?}

Uno de ellos puede ser la distinción entre embrión en tubo de ensayo y embrión implantado. La evolución natural de un embrión en un tubo de ensayo sólo es la reproducción celular vegetativa indiferenciada o bien la muerte celular si no se adoptan las adecuadas precauciones. En cambio, un embrión implantado en un útero materno inicia decididamente el programa de generación de un nuevo individuo. Parece claro que pueden tener dos categorías éticas diferentes. Más espinoso de resolver parece el matiz de la edad del embrión, puesto que es díficil marcar una frontera temporal que delimite al embrión-célula del embrión-ser humano (o ser humano en potencia). Ya sabemos que la visión del valor intrínseco afirma que esta matización no tiene sentido, puesto que la dignidad humana la adquiere el embrión desde el mismo momento de la concepción. Sin embargo, hay suficientes datos, desde la ciencia al derecho, que plantean que el tiempo sí puede ser un factor que se debe valorar, de acuerdo con la visión gradualista o ambiental. Así, se sabe con certeza que hasta los 14 días no se puede distinguir entre células que darán lugar al nuevo individuo y las células auxiliares que formarán la placenta, órgano que no es parte del nuevo ser. Desde el derecho, en muchos países se ha legislado sobre confrontaciones de derechos que van mucho más allá de las 2 semanas citadas ${ }^{1}$, afrontando pragmáticamente, en mayor o menor medida, problemas sociales candentes.

Otra matización importante es la metodología empleada. La metodología debe ser el

1 Véase, desde diferentes constituciones, las regulaciones sobre el derecho al aborto. primer referente ético para cualquier científico. Hay suficiente consenso en que no se deben utilizar métodos deficientemente desarrollados, o con pocos controles, o sin suficientes garantías de éxito, entre otros, y que todos los proyectos deberían ser validados por los comités de ética de las diferentes instituciones donde deberán llevarse a cabo. De ahí la importancia de que el sector público tome la primacía que le corresponde en este campo del conocimiento, dado que las garantías que ofrece son infinitamente superiores a las que se suelen exigir en el seno de las compañías biotecnológicas privadas. En éstas, como es lógico, las consideraciones de rentabilidad económica son prioritarias y ya se está viendo cómo se suelen embarcar en proyectos de gran impacto mediático aunque muy poco rigurosos científicamente, con el fin de condicionar psicológicamente a los mercados de capitales de los que dependen.

En principio, cuando se admite la clonación terapéutica se acepta la superioridad de la transferencia de núcleo de célula somática para la generación del embrión, tanto desde el punto de vista que permite mayores aplicaciones científicas como porque permite obviar objeciones éticas en determinados círculos que pueden suponer, como ya hemos visto, la producción de embriones gaméticos para fines terapéuticos o de investigación.

Finalmente, está el matiz del fin que se le quiera dar al embrión con las técnicas de clonación. Hay consenso generalizado en rechazar el fin reproductivo, al menos por ahora. Serias dudas hay sobre la selección de sexo o caracteres, que puede introducir aspectos de frivolidad y eugenesia irresponsable. Sin embargo, se ha de matizar según cada caso, y ésta es la regla de oro que se ha de aplicar en estos temas: la valoración individualizada según las circunstancias que rodean a cada pregunta y huyendo de respuestas generales. Así pocos, 
con seriedad, plantearían objeciones a la selección por aberraciones genéticas, o a la del sexo cuando va ligado a alguna de estas aberraciones. Gran consenso hay, como hemos dicho antes, en el mundo de la ciencia en aceptar fines de investigación o terapéuticos sobre la base de proyectos científicamente rigurosos y con exhaustivos controles por parte de organismos públicos (derivados, por tanto, de la misma representación democrática de la sociedad). Por ello, es vital que el financiamiento proceda en su mayoría de fondos públicos. Es más, es discutible éticamente la iniciativa privada no controlada en temas que, con tanta trascendencia, pueden afectar al futuro del ser humano.

Y para terminar,

\section{¿Tienen sentido las posturas unilaterales?}

Con esta cuestión nos estamos planteando el hipotético o real caso de un país que, tras un serio debate con participación de todas las esferas de reflexión implicadas, decidiera adoptar una serie de medidas legislativas para prohibir las técnicas de clonación por considerar que atentan contra los fundamentos éticos de su sociedad. Sucedería que, probablemente, existirían a su alrededor otros países cuyas sociedades podrían haber enfocado el tema de otra manera y permitido el desarrollo de estas técnicas. El caso es real, ya que países como el Reino Unido, Suecia y, dentro de poco, Francia, han aprobado leyes que permiten las técnicas de la clonación terapéutica. ¿Cuál puede ser la consecuencia? La fuga de científicos interesados en ellas, el traslado de usuarios (que se lo puedan permitir) cuando las aplicaciones terapéuticas sean una realidad y, también, el distanciamiento científico y tecnológico entre los dos tipos de países. Hay casos más flagrantes, como el que un país prohíba el desarrollo de estos métodos en su territorio, pero permita la importación de células madre obtenidas por los mismos métodos en otros países. Y el caso extremo y más escandaloso desde el punto de vista moral: que un país, el más avanzado de todos en esta parcela del conocimiento, como es EE.UU., prohíba tajantemente todos estos métodos en sus instituciones y con sus fondos públicos por considerarlos éticamente inaceptables, pero permita (y hasta aliente) la iniciativa privada en los mismos.

Realmente, no tienen sentido las posturas unilaterales.

\section{Conclusión}

La metodología de la clonación terapéutica para la obtención de células madre que abra el camino de la medicina regenerativa ha creado grandes esperanzas. Tanto entre los enfermos de graves enfermedades invalidantes, que ven de nuevo una luz a sus males tras años en que se ha hablado mucho de terapia génica pero sin acabar de concretarse en opciones terapéuticas reales-, como entre los científicos, que tienen ante sí herramientas muy poderosas para profundizar en el conocimiento de los mecanismos de la diferenciación celular. También ha abierto un aguerrido debate acerca de la profanación, por estas metodologías, de barreras éticas y religiosas hasta ahora infranqueables para gran parte de la sociedad. Nos enfrentamos a un problema en el que las posturas ideológicas preconcebidas y la superficialidad mediática propia de nuestro tiempo no ayudan precisamente al objetivo de lograr consensos que permitan el avance razonable y controlado del conocimiento científico. Nos enfrentamos también a un conflicto de derechos, en el cual los dirigentes de nuestras sociedades tendrán que escoger prioridades y asumir la responsabilidad de su elección, a saber, la confrontación entre el respeto a la dig- 
nidad de los seres humanos unicelulares y el derecho de miles de personas enfermas a tener una esperanza de curación aprovechando los conocimientos de la sociedad en la que viven y a la que contribuyen.
Finalmente, creemos que cuando los grandes dilemas irresolubles se concretan en problemas acotados e individualizados, es más fácil acordar soluciones razonables para todos, aportando pragmatismo y sentido común a cada situación.

\section{Bibliografía}

Abel F. Embrió humà i medicina regenerativa. Meravella de les meravelles. Bioètica \& Debat. Tribuna oberta de l'Institut Borja de Bioètica 2000; 22:1-5.

Evers K. European Perspectives on therapeutic cloning. New England Journal of Medicine 2002; 346:15791582.

Lacadena JR. Embriones humanos y cultivos de tejidos: reflexiones científicas, éticas y jurídicas. Revista de Derecho y Genoma Humano 2000; 12:191-212.

López C. No cerrar puertas. El País. Madrid, 2 de diciembre de 2001: 21.

López Moratalla N. Demasiadas Inseguridades. El País. Madrid, 2 de diciembre de 2001: 21.

Raya A, Izpisúa C. ¿Qué podemos hacer con las células? El País, Supl. Dom. Madrid, 2 de diciembre de 2001: 3 .

Sampedro J. Próxima meta: clonación de seres humanos. El País, Supl. Dom. Madrid, 2 de diciembre de 2001: 1-3.

Soria B y Juan V. Células madre, embriones y clonación: ¿el nacimiento de un nuevo paradigma? El País. Madrid, 16 de enero de 2002: 24.

Vogelstein B. When a clone is not a clone. HMS Beagle 2002; 118.

Weissman IL. Stem cells - scientific, medical and political issues. New England Journal of Medicine 2002; 346: 1576-1579.

Wertz DC. Embryo and stem cell research in the USA: a political history. Trends in Molecular Medicine 2002; 8: 143-146. 